Pesq. Vet. Bras. 30(8):637-640, agosto 2010

\title{
Mionecrose aguda por Clostridium septicum em equinos ${ }^{1}$
}

\author{
Djeison Lutier Raymundo' ${ }^{2}$ Saulo Petinatti Pavarini' ${ }^{2}$, Pedro Soares Bezerra \\ Junior $^{3}$, Nadia Aline Bobbi Antoniassi ${ }^{2}$, Paulo Mota Bandarra², Bernardo \\ Stefano Bercht ${ }^{4}$, Marcos José Pereira Gomes ${ }^{4}$ e David Driemeier ${ }^{2}$
}

\begin{abstract}
Raymundo D.L., Pavarini S.P., Bezerra Junior P.S., Antoniassi N.A.B., Brecht, B.S, Gomes M.J.P. \& Driemeier D. 2010. [Acute myonecrosis by Clostridium septicum in horses.] Mionecrose aguda por Clostridium septicum em equinos. Pesquisa Veterinária Brasileira 30(8):637-640. Departamento de Patologia Clínica Veterinária, Universidade Federal do Rio Grande do Sul, Av. Bento Gonçalves 9090, Porto Alegre, RS 91540-000, Brazil. E-mail: davetpat@ufrgs.br

Two cases of acute necrotizing myositis caused by Clostridium septicum in horses are described. Both horses presented swelling of the right pelvic limb extending to the ventral abdominal region. The cut surface of the affected area revealed blood-stained edema and gas bubbles. The skeletal muscles of the caudal region of the thigh of the affect limbs had dark red discolored areas of blood-stained edema and crepitation; the deep musculature was dry. The main histopathological findings were swelling, vacuolation and hyaline and floccular necrosis of skeletal myofibers; in between myofibers there were hemorrhage, edema and large amounts of bacilli. In both cases, $C$. septicum was isolated from the edema fluid of muscular lesions.
\end{abstract}

INDEX TERMS: Diseases of horses, Clostridium septicum, necrotizing myositis, myonecrosis.

RESUMO-- Descrevem-se dois casos de miosite necrosante causada por Clostridium septicum em equinos. Os dois equinos apresentavam aumento de volume no membro pélvico direito e que se estendia para a região abdominal ventral. Ao corte, essa área era formada por edema sanguinolento e bolhas de gás. Os músculos esqueléticos da região caudal da coxa apresentavam áreas vermelho-escuras, crepitantes, com edema sanguinolento e, ao corte, as áreas mais profundas da musculatura tinham aspecto seco. As principais alterações histopatológicas observadas foram tumefação, vacuolização, necrose hialina e necrose flocular de fibras

\footnotetext{
${ }^{1}$ Recebido em 23 de março de 2010.

Aceito para publicação em 1 de abril de 2010.

Parte da Tese de Doutorado do primeiro autor, Programa de PósGraduação em Ciências Veterinárias, Universidade Federal do Rio Grande do Sul (UFRGS), Av. Bento Gonçalves 9090, Porto Alegre, RS 95320-000, Brasil.

2 Setor de Patologia Veterinária (SPV), Departamento de Patologia Clínica Veterinária, UFRGS, Porto Alegre, RS. *Autor para correspondência: davetpat@ufrgs.br

3 Patologia Veterinária, Departamento de Medicina Veterinária, Universidade Federal de Lavras (UFLA), Cx. Postal 3037, Lavras, MG 37200-000, Brasil.

4 Laboratório de Bacteriologia, Departamento de Patologia Clínica Veterinária, UFRGS, Porto Alegre, RS.
}

musculares esqueléticas. Entre as fibras, havia hemorragia, edema e grande quantidade de bacilos com tamanho de 3-6 $\mu \mathrm{m}$. Na coloração de Gram, os bacilos se apresentavam roxos (gram-positivos); quando impregnados pela prata (Warthin-Starry), se mostraram enegrecidos. Nos dois casos, C. septicum foi isolado, em ambiente anaeróbio, do líquido de edema das lesões musculares.

TERMOS DE INDEXAÇÃO: Doenças de equinos, Clostridium septicum, miosite necrosante, mionecrose.

\section{INTRODUÇÃO}

Miosite por clostrídios, mionecrose e edema maligno são algumas das denominações utilizadas para designar infecções necrosantes em tecidos moles associadas a Clostridium spp. em equinos (Peek et al. 2003). Em animais de produção, essas lesões podem estar associadas com castração, tosquia, feridas penetrantes, injeções e lesões relacionadas à parição (Radostits et al. 2007). A mionecrose é frequentemente observada em bovinos, ovinos e caprinos, que são as espécies mais suscetíveis. Suínos e equinos apresentam menor susceptibilidade. Em equinos, $C$. perfringens e $C$. septicum são as bactérias mais frequentemente observadas em casos de mionecrose (Jeanes et al. 2001, Peek et al. 2003), mas C. chavoei (Hagemoser et al. 
1980), C. novy (Graham, 1940) e C. fallax (Cooloe et al. 1983) também ocorrem nesses casos. C. septicum é um bacilo gram-positivo grande (tamanhos de 3-6 $\mu \mathrm{m}$ ), móvel e anaeróbico obrigatório (Odendaal \& Kriek 2004) que produz quatro diferentes toxinas. A mais importante, alfa toxina, é hemolítica e necrótica e, em associação com as outras toxinas, causa danos ao endotélio vascular e membrana plasmática muscular (Rebhun et al. 1985, Perdrizet et al, 1987). Os animais afetados desenvolvem os sinais clínicos em aproximadamente 48 horas após a inoculação ou injúria (Jeanes et al. 2001) e apresentam febre, depressão, toxemia e inchaço muscular, muitas vezes, com dor associada. Essa lesão muscular inicialmente se apresenta hiperêmica, quente, macia e delimitada; posteriormente se torna escura, fria, firme e necrosada (Reed, 1955, Rebhun et al. 1985). Em muitos casos, o exame de palpação do local afetado revela acumulo de gás no tecido subcutâneo e músculos adjacentes; entretanto, pode estar ausente (Perdrizet et al. 1987, Jeanes et al. 2001). Na necropsia, observa-se grande quantidade de líquido inflamatório serosanguinolento no tecido subcutâneo. Em alguns casos, há apenas grande quantidade de gás no tecido subcutâneo e fáscias sem lesão muscular, a qual, quando presente é caracterizada por intensa miosite necrótica (Odendaal \& Kriek 2004). Este trabalho relata os achados clínico-patológicos observados em dois casos de mionecrose aguda em equinos associados com infecções por $C$. septicum.

\section{MATERIAL E MÉTODOS}

Um equino Quarto de Milha, macho de 7 anos de idade (Equino 1) e outro, Crioulo, macho de 4 anos de idade (Equino 2), foram necropsiados pelo Setor de Patologia Veterinária da Universidade Federal do Rio Grande do Sul (SPV-UFRGS). Os dados da evolução da doença e sinais clínicos foram obtidos com o veterinário e proprietários responsáveis. Durante a necropsia, amostras de tecidos foram coletadas, fixadas em solução de formalina tamponada a $10 \%$, processadas pelas técnicas rotineiras de histopatologia, cortadas na espessura de $5 \mu \mathrm{m}$ e coradas pela técnica de hematoxilina e eosina (HE). Cortes de músculos esqueléticos foram também corados pela técnica de Gram e Warthin-Starry. Amostras de líquido de edema serosanguinolento foram coletadas da região subcutânea dos dois equinos, mantidas sob refrigeração e encaminhadas para cultivo microbiológico. Esses materiais foram inoculados por punção direta com a alça de platina e semeados em ágar sangue ( $7 \%$ de sangue ovino) e ágar Maconkey. As placas foram incubadas a $37^{\circ} \mathrm{C}$ em ambientes aeróbico e anaeróbico, com utilização do envelope AnaeroGen.

\section{RESULTADOS}

O Equino 1 apresentou aumento de volume no membro pélvico direito e cólica antes da morte. Três dias antes, esse animal tinha perdido a ferradura do membro torácico esquerdo, quando foi iniciado tratamento com antiinflamatório intramuscular. O Equino 2 estava há quarenta dias sendo preparado para apresentação, período no qual apresentou emagrecimento progressivo. Quinze dias antes da morte, hepatoprotetor e antiparasitário foram administrados intramuscularmente. No dia que antecedeu a morte, esse animal apresentava dificuldade de locomoção, ou relutância ao movimento. Imediatamente, recebeu antiinflamatório e demonstrou melhora leve do quadro clínico. No dia seguinte, o animal estava agonizando e com aumento de volume no membro pélvico direito, imediatamente antes da morte. Durante as necropsias dos dois equinos, observouse aumento de volume nos membros pélvicos direitos que se estendiam até a região abdominal ventral (Fig.1). Ao toque, esses aumentos apresentavam crepitação que deixava uma depressão sob a pressão de um dedo (sinal de godê) (Fig.2). Ao corte, essas áreas apresentavam edema sanguinolento e bolhas de gás subcutâneo e intramuscular. Os músculos esqueléticos tinham áreas vermelho-escuras, crepitantes, com edema sanguinolento e, ao corte, aspecto seco (Fig.3). No Equino 1, essa alteração foi observada nos músculos grácil, semi-membranáceo, glúteo bíceps, quadríceps femoral e glúteo superficial. No Equino 2, os músculos afetados incluíam glúteos superficial, acessório e

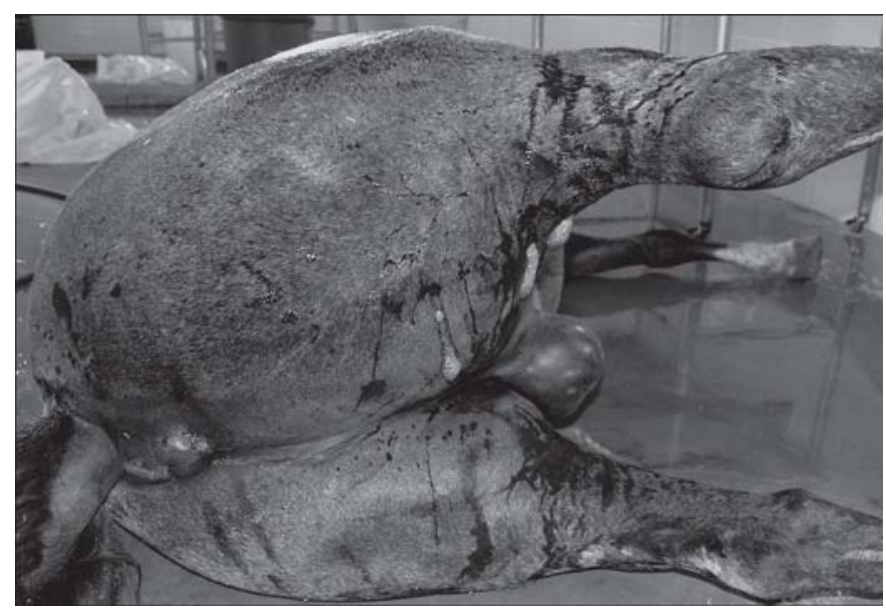

Fig.1. Equino. Mionecrose por Clostridium septicum. Aumento de volume do membro pélvico direito com extravasamento de liquido serossanguinolento.

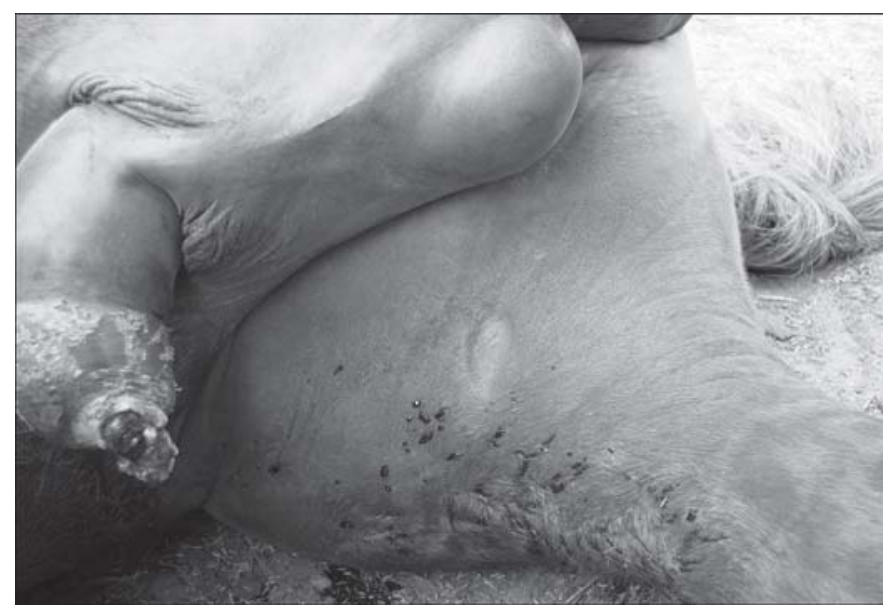

Fig.2. Equino. Mionecrose por Clostridium septicum. Membro pélvico direito com edema e crepitante ao toque. 

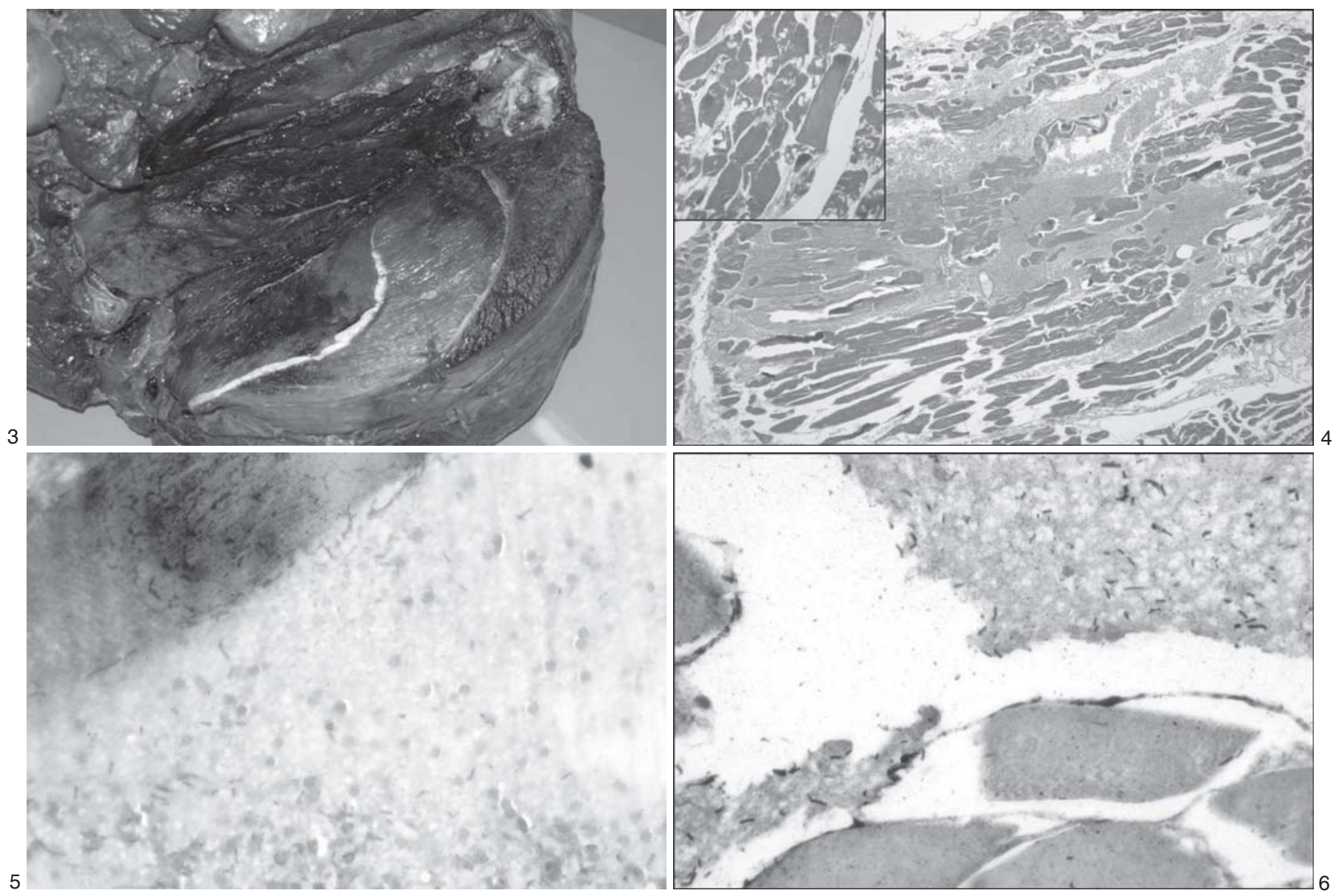

Fig.3. Equino. Mionecrose por Clostridium septicum. Músculo semimembranáceo. Áreas vermelho-escuras, crepitantes e com edema sanguinolento. Ao corte, aspecto seco.

Fig.5. Equino. Mionecrose por Clostridium septicum. Músculo esquelético. Grande quantidade de bacilos Gram-positivos nas áreas de necrose muscular. Gram, obj.40x.

médio, além de grácil e quadríceps femoral. No coração de ambos os equinos, observou-se petéquias na superfície epicárdica e, no Equino 2, líquido serosanguinolento no interior do saco pericárdico. Os pulmões estavam congestos, com edema e petéquias subpleurais nos dois equinos. No exame histopatológico dos músculos esqueléticos afetados de ambos os equinos, observaram-se diversos graus de tumefação e vacuolização de fibras e numerosas fibras com necrose hialina e flocular. Entre as fibras musculares, havia edema e hemorragia, grande quantidade de bacilos e áreas de enfisema com discreto infiltrado de neutrófilos e monócitos (Fig.4) Na pele, havia congestão difusa acentuada, edema, hemorragia e enfisema com grande número de bacilos. Pela técnica de coloração de Gram, os bacilos se apresentaram roxos, coloração características de bactérias gram-positivas (Fig.5). Na técnica de impregnação pela prata (Warthin-Starry), esses bacilos se apresentaram enegre-

Fig.4. Equino. Mionecrose por Clostridium septicum. Músculo esquelético. Tumefação, vacuolização e necrose hialina e flocular de fibras musculares. Entre as fibras musculares, observa-se edema, hemorragia e áreas de enfisema com infiltrado de neutrófilos e monócitos. Coloração HE, obj.10x.

Fig.6. Equino. Mionecrose por Clostridium septicum. Músculo esquelético. Grande quantidade de bacilos de coloração enegrecida em meio às áreas de necrose muscular. WarthinStarry, obj.40x.

cidos (Fig.6). No exame microbiológico, observou-se em coloração direta do músculo, grande quantidade de células vegetativas, algumas esporuladas, compatíveis com Clostridium sp. Não houve qualquer crescimento em aerobiose; entretanto, após 48 horas, em ambiente anaeróbico, foi observado crescimento de incontáveis colônias ß-hemolíticas com coloração branco-acizentadas, com bordos irregulares e crescimento em ondas. A coloração de Gram evidenciou esporos ovais e subterminais. Na microscopia de fase, observou-se motilidade. C. septicum foi isolado e identificado pelas características morfotintoriais e culturais.

\section{DISCUSSÃO}

O diagnóstico de mionecrose aguda por Clostridium septicum nos dois equinos foi estabelecido pelos achados de necropsia e histopatologia e confirmado pelo isolamento microbiológico do agente a partir do líquido de edema 
das lesões. Os dois equinos deste trabalho infectados por C. septicum foram tratados com medicamentos injetáveis intramusculares, forma de inoculação do bacilo descrita na literatura como mais frequente (Rebhun et al.1985, Peek et al. 2003). As regiões descritas como mais frequentemente afetadas incluem pescoço (músculo cervical), peito (peitoral) e membro pélvico (glúteos, semimembranáceo e semitendináceo); locais de eleição para aplicações intramusculares em equinos (Peek et al. 2003 ). Nos dois casos, a lesão se desenvolveu na região do membro pélvico e afetou principalmente músculos da região dorso-caudal da coxa, localização descrita por diversos autores como uma das regularmente afetadas por miosite necrosante em equinos; contudo associada à prevalência mais baixa (25\%) do que a região cervical (71\%) (Jeanes et al. 2001). Os dois equinos apresentaram evoluções clínicas distintas, o histórico do Equino 1 indica uma possível infecção pelo agente cerca de três dias antes da morte: enquanto que, no Equino 2, a inoculação parece ter ocorrido cerca de 15 dias antes. Os dois equinos apresentaram aumento de volume muscular um dia antes da morte. Muitos autores descrevem a infecção por Clostridium spp. em equinos com evolução aguda, de 24-48 horas (Rebhun et al. 1985, Brown et al. 1988, Peek et al. 2003); entretanto alguns equinos têm apresentado períodos maiores de evolução, de até duas semanas (Perdrizet et al. 1987). As lesões musculares encontradas na necropsia dos dois equinos são semelhantes às descritas previamente (Peek et al. 2003). A lesão inflamatória e necrótica da musculatura afetava área extensa e acometia diversos músculos. A maioria dos relatos sobre miosites necróticas em equinos se refere à infecção por $C$. septicum ou $C$. perfringens (Jeanes et al. 2001, Peek et al. 2003). Como esses casos apresentam uma evolução muito aguda é extremamente importante adotar medidas preventivas para evitar a infecção, pois o tratamento só é eficiente quando realizado nos estágios iniciais da doença (Peek et al. 2003). Medidas como higienização do local de aplicação de injeções, utilização de agulhas limpas e instituição de terapia antimicrobiana em casos de lesões perfurantes ou formação de porta de entrada para bactérias são indicadas (Brown et al. 1988).

Agradecimentos.- Ao CNPq e à CAPES, pela concessão de bolsas aos mestrandos e doutorandos do Setor de Patologia Veterinária. Ao médico veterinário Fernando Gonzáles, pelo encaminhamento dos equinos para necropsia e informações complementares sobre os casos. Ao professor Cláudio Estêvão Farias da Cruz, pela revisão deste artigo.

\section{REFERÊNCIAS}

Brown C.M., Kaneene J.B. \& Walker R.D. 1988. Intramuscular injection techniques and the development of clostridial myositis or cellulites in horse. J. Am. Vet. Med. Assoc. 193(6):668-670.

Cooloe P.J., Ireland L. \& Vaudery J.C. 1983. Clostridium fallax as a cause of gas-oedema in a horse. J. Comp. Pathol. 93:595-601.

Graham R. 1940. Reactions in horses following inoculation of a chickembryo vaccine. J. Am. Vet. Med. Assoc. 97:38-39.

Hagemoser W.A., Hoffman L.J. \& Lundvall R.L. 1980. Clostridium chavoei infection in a horse. J. Am. Vet. Med. Assoc. 176:631-633.

Jeanes L.V., Magdesian K.G., Madigan J.E. \& Meagher D. 2001. Clostridial myonecrosis in horses. Comp. Cont. Educ. Pract. Vet. 23(6):577-587.

Kriek N.P.J. \& Odendaal M.W. 2004. Clostridium chauvoei infections, p.1856-1862. In: Coetzer J.A.W. \& Tustin R.C. (Eds), Infectious Diseases of Livestock. Vol.3. $2^{\text {nd }}$ ed. Oxford University Press, Cape Town.

Odendaal M.W. \& Kriek N.P.J. 2004. Clostridium septicum infections, p.1869-1873. In: Coetzer J.A.W. \& Tustin R.C. (Eds), Infectious Diseases of Livestock. Vol.3. $2^{\text {nd }}$ ed. Oxford University Press, Cape Town.

Peek S.F., Semrad S.D. \& Perkins G.A. 2003. Clostridial myonecrosis in horses (37 cases 1985-2000). Equine Vet. J. 35(1):86-92.

Perdrizet J.A., Callihan D.R., Rebhun W.C. \& Shin, S.J. 1987. Successful management of malignant edema caused by Clostridium septicum in a horse. Cornell Vet. 77(4):328-338.

Radostits O.M., Gay C.C., Hinchcliff K.W. \& Constable P.D. 2007. Diseases associated with bacteria - II, p.830-832. In: Ibid (Eds), Veterinary Medicine: A textbook of the diseases of cattle, horses, sheep, pigs and goats. Saunders Elsevier, Philadelphia.

Rebhun W.C., Shin S.J., King J.M., Baum K.H. \& Patten V. 1985. Malignant edema in horses. J. Am. Vet. Med. Assoc. 187(7):732-736.

Reed C.H. 1955. Malignant edema infection in a horse. Calif. Vet. 8:30-33. 